\title{
Factors Influencing Clients in Choosing Insurance Companies
}

\author{
Bernardus Franco Maseke, Dietilde Ndinelago Iipinge \\ Faculty of Economics and Management Science, University of Namibia, Keetmanshoop, Namibia \\ Email: fmaseke@gmail.com, dietilde079@gmail.com
}

How to cite this paper: Maseke, B.F. and Iipinge, D.N. (2021) Factors Influencing Clients in Choosing Insurance Companies. Open Access Library Journal, 8: e6944. https://doi.org/10.4236/oalib.1106944

Received: October 28, 2020

Accepted: January 26, 2021

Published: January 29, 2021

Copyright () 2021 by author(s) and Open Access Library Inc.

This work is licensed under the Creative Commons Attribution International License (CC BY 4.0).

http://creativecommons.org/licenses/by/4.0/ (c) (i) Open Access

\begin{abstract}
The paper was conducted to analyze different factors influencing clients' choice of insurance companies. Insurance is essential for peace of mind, however, clients should be cautious when choosing insurers to avoid future disappointments. Clients should also be aware of fake agents, misrepresentation of information, fraud and coercion by agents and brokers. The main objective of this paper was to identify the factors that drive clients' preferences in selecting insurance companies, whilst the second objective was to determine the relative importance of these particular factors (advertising, social and behavioral factors). This paper followed a survey design with questionnaires and 185 randomly selected participants from Keetmanshoop Namibia. The results showed that majority of participants chose insurers as a result of agents/broker persuasion, which is similar to what the majority of other researchers found in previous studies. None the less, $87 \%$ of participants are satisfied with their current insurers, leaving $13 \%$ unsatisfied and intending to switch to other insurers. In addition findings revealed a positive relationship between client's relative importance of insurance and factors (social, advertising and behavioral factors).
\end{abstract}

\section{Subject Areas}

Economics

\section{Keywords}

Insurance, Policyholders, Preferences

\section{Introduction}

There is globally a huge variety of insurance companies and insurance products clients can procure from. Therefore, clients may find it challenging to choose the 
right insurer for their insurance needs or correct type of insurance policy. For this reason, insurance companies advertising focused on social and behavioral factors that influence clients when choosing insurance companies (Bonner, 2018) [1]. Bonner (2008) [1] further suggested that due to the big pool of insurance companies and products available consumers subconsciously make insurance choices based on factors that always influence other buying decisions to aid them in making the right company or product choice.

Several researchers stated that, in most cases there is usually a positive relationship between these factors and the consumers' choice of insurance companies. (Banerjee, 2015) [2] emphasized that, the act of buying looked at just another run of the million financial actions that the consumer will take. As an illustration, the consumers put a value to their lives but when it comes to choosing insurance companies, they have to do some number crunching. In most cases, the consumers are looking for the less expensive insurers, however, they always make sure they choose companies that offer a pricing that complements their financial plan to avoid going above their budget (Banerjee, 2015) [2].

The paper published by (Wand, 2017) alluded that, the factors that affect clients in the United States include social factors which is very important, that include the insurance agents' ability to establish a rapport with customers. This is provided that, insurance clients are not going to choose agents who lack industry knowledge, come across as uncaring salespeople or that cannot provide legal contracts to back their products and services (Tucker, 2019) [3].

This paper identified two important factors that influence client's preference of insurers for their policies. These are policyholder's preferences and factors that influence policyholder's preference of insurance companies (social, advertising and behavioral factors). The policyholders were the dependent variables and the factors were the independent variables. In that case, policyholders depend on these factors to make decisions. Findings revealed how these factors influence clients in choosing insurers, which was not really covered by previous researchers. Additionally, this paper informed potential and current clients on how to identify dishonest and fake insurance agents and brokers.

\section{The paper is grounded on the following research objectives:}

1) To explore if policyholder's preference of insurance companies is influenced by (social, advertising and behavioral factors) in Namibia.

2) To determine the relative importance of social, advertising and behavioral factors on insurers and insureds.

\section{Literature Review}

\subsection{Factors That Drive Clients in Choosing Insurance Companies for Their Policies/Insurance Products}

(Tadesse, 2014) [4], the researcher did a study on the factors that influence the choice of insurance services in selected insurance companies in Jimma town, whereby the researcher found out that affordable premiums are one of the sig- 
nificant factors that clients look at. On a contrary, private insurance company, public insurance companies, attractiveness of the branch office facility, the availability of information and parking space and promotional activity were the least insurance companies' selection criteria by clients. Whereas, the most considered factors were, the financial soundness and the reputation of the company.

(Mathur \& Tripathi, 2014) [5], similarly found out most of the influential factors that the previous researcher came across. The researchers looked at the top 10 most important factors that influence clients, namely, computerization and online transactions, connectivity with the banks, speed and efficiency of transactions, clear communication, availability of ATM in nearby and several locations, reputation of the company, professionalism and credibility of staff, fast and efficient counter services, ease of opening the account and secured internet banking as per according to the data collected. Whereas, the researchers found out that, the least important factors that clients focus on includes, influential marketing campaign, free gifts for customers peer group impression and overdraft privileges on current accounts.

(Rajkumar \& Kannan, 2014) [6], in the researchers' empirical paper titled the factors affecting customer's preferences for selection of life insurance companies, researchers identically determined the important factors which influence clients when selecting particular companies for buying insurance policies. The researchers found out that, most of the clients' decisions to choose insurance companies were influenced by the agents or brokers. Comparing to what (Mathur \& Tripathi, 2014) [5] found out, the two researchers similarly confirmed that e-commerce and online transactions are significant when it comes to the clients' choices. On a contrary, (Rajkumar \& Kannan, 2014) [6], as well proved that the internet proved to be the most important reason why clients buy insurance products or choose insurance companies. Similarly, they as well stated that friends' suggestions and advices as well influence their selection decisions just like other researchers confirmed that.

(Suneja \& Sharma, 2015) [7], Unlike other previous studies, they found out that the most important factor that affect clients was promotional activities which was basically the least important factor according to (Mathur \& Tripathi, 2014) [5] in their study. Besides, (Rajkumar \& Kannan, 2014) [6] similarly found out how relevant promotional activities are. According to the researchers' findings, clients as well get influenced by the premium and procedural formalities in contrast with the previous study as clients gave the same feedback in (Tadesse, 2014) [4]'s findings.

\subsection{The Relative Importance of Social, Advertising and Behavioral Factors on Insurers and Insureds}

(Mathur \& Tripathi, 2014) [5], in their paper titled the factors influencing customers' choice of insurance companies, the researchers explored that insurance institutions need to create a lucrative customer base which will increase their market share and the need to identify factors that influence the choice of insur- 
ance companies' selection and work on improving them. Since customers are becoming more demanding and sophisticated, it is important for the insurance sector to determine the factors which are pertinent to the customers for choosing a company. Equally important, in order to prevent the migration of clients and attracting the new ones, it is vital for the insurance companies to understand the preferences of the customers to offer the services required by them. Moreover, (Mathur \& Tripathi, 2014) [5] stated that, with intensified competition in the industry, it is crucial for the insurers to understand how customers choose their insurance companies. Significantly, exploring and evaluating such information will help companies to identify the appropriate marketing strategies that are needed to sustain and survive in the market.

(Sharma, 2015) [8], the researcher warned insurance companies on the vitality of the image of the company as a factor. (Sharma, 2015) [8] explained that, this feature is considered important by the customers as the insurance products are quite comprehensive and can be customized as per the need of customers. In addition, consumer markets can be segmented on several bases. Therefore, the segmentation of customer markets helps insurance companies to discriminate insurance products in desired categories, so that customers' needs and wants may be effectively addressed for the purpose of preparing sound and effective marketing strategies for the company. Henceforth, the consumer market can be segmented on the basis of demographic disparities and thus, the impact of these variables on the influence of customers' choices and the need to be evaluated. Equally important, the improper identification of true determinants of consumers' companies' selection decision may result in losing potential customers.

(Martins, 2018), In the researcher's article titled: Choosing an insurance company, 10 factors to consider, the researcher informed clients that they should not have a goal to find a company with $100 \%$ positive reviews, the goal should be to look out for negative reviews and find out the nature of the problems those agitated clients had with a particular insurance company. It is significant for them to know that if the company has problems with the non-compensation of its policy holders that is a red flag that the clients should not do business with that company. However, the researcher advised clients to consider the reputation of the company. In addition, when it comes to the legal accreditation of the company, the researcher stated that, it is very important to choose the insurer that is accredited by the government and recognized as well to avoid fraud.

\section{Methodology}

This paper was grounded on a quantitative research method which was found to be more appropriate compared to the other research method. In line with that, the researchers made use of a positivism research philosophy which proved to be monumental for the study. Moreover, this paper used the deductive approach in emerging the data that was collected. A survey strategy was implied, whereby 185 questionnaires using simple random sampling were distributed to policy- 
holders around Keetmanshoop in order to answer the research objectives of the research project.

\subsection{Sampling}

This paper utilized a cluster sampling method. Whilst collecting data, the researchers looked at specific characteristics in the respondents, (must be a policyholder), whereas, the researchers took the tailored sample that was in proportion to the population of interest. According to (Omniconvert, 2019) [9], a sample size is a term used in market research for defining the number of subjects included in a sample. Similarly, by sample we should be able to understand a group of subjects that are selected from the general population and is considered as a representative of the true population for that specific paper. In essence, simple random sampling was used to sample policyholders according to (Graff, 2018) [10]. At a confidence interval of $95 \%$ using the statistical formula $s^{2}=\Sigma\left(x_{i}\right.$ $-x)^{2} /(n-1) 185$ participants were selected from a population of 6000 policyholders.

\subsection{Research Instruments}

Both structured and unstructured questions were used as the research instruments of the paper. (Farooq, 2013) [11] defined structured questionnaire as the type of questionnaire which has pre-determined questions with answers. The respondents only tick the correct answer in short (Yes or No). They are as well referred to as pre-coded, closed restricted and categorical questionnaire. Whereas, unstructured questionnaires are defined as, those questions in which pre-determined questions are given but have no answers. Moreover, these answers are to be structured by the respondents. Open questions are given for the respondents to give answers. Subsequently, in such type of questionnaire, interview between the researcher and respondents or face to face conversation takes place. Such types of questionnaires are also called open-ended, unrestricted or non-categorical questionnaire (Farooq, 2013) [11].

\section{Validity and Reliability}

A pilot study was used to ensure both validity and reliability of the instrument. According to the (Journal of Hayat, 2014), a pilot study is referred to as a small-scale of a complete survey or a pretest for a particular research instrument. In that case, the researchers conducted a pilot test to ensure the validity and reliability of the data that was derived from the survey questions. Various methods used during the pilot study are discussed below.

\section{1) Validity}

Liu, (2010) defined validity as the degree to which research instruments accurately measure what it intends to measure. (Morgan, 2015) suggested that, for the researcher to establish the validity of the measure that he/she is trying to develop, it is better to conduct a small pilot study. The researchers give the questionnaires to senior academic professionals to ensure that they were all valid and 
capable of providing the most needed information for the paper. Markedly, the researchers incorporated face validity, which represents the simplest or the least scientific form of validity and it is based on the normative judgment of the researcher to see whether the scale measures what it claims to measure (Gyasi, 2015) [10].

\section{2) Reliability}

Reliability is defined as the degree in which research instruments yield consistent results. It is as well concerned with the question of whether the results of the study will be repeatable (Liu, 2010). With that being mentioned, the researchers made use of consistency reliability that looked at the consistency of the score of individual items on an instrument, with the scores of a set of items, or subscale which typically consisted of diverse items that measured the single contract. Alongside with that, the researchers exerted the retest reliability in order to make sure that the information given was reliable. Significantly, the researchers made use of inter-ratter reliability to check out the degree of agreement between the participants. This means that, it was very possible to test the data that was implemented by the policyholders that participated in the study. This was done through a pre and post pilot study using multiple raters which compared the scores of the results and a mean agreement score of 73 was obtained.

\subsection{Data Analysis}

Percentiles and the mean scores were used to analyze the data collected from the questionnaire. In particular frequency tabulation, measures of percentages, and mean scores were used to make the results more accurate. Frequency and percentage distribution were used to analyze the demographic characteristics including the rest of the questions in the survey.

\section{Results and Findings}

\subsection{Summary of Data}

Concentrating on the three independent variables, the researchers were able to discuss the findings. The three variables are social factors, advertising factors and behavioral factors.

Variable 1: Social factors

The findings articulated that clients have a negative relationship when it comes to social factors. Only a little number of participants indicated that they were influenced by social factors in their preference decisions. The results indicated that, clients were not influenced by any colleagues, friends, relatives or family members. However, majority of the participants elaborated that they were influenced by brokers/agents.

Variable 2: Advertising factors.

Majority of the clients stipulated that they were influenced by advertising factors with promotional activities providing enough satisfactions to clients. Therefore, there is a positive relationship between advertising factors and cus- 
tomers' preference of insurance companies.

Variable 3: Behavioral factors.

The data analysis pointed out that, clients are often influenced by behavioral factors, which includes, professionalism of agents, efficient and speed transactions, trust in the company etc. Majority of the respondents pointed out that they were influenced by the trust they have in the companies. So forth, there is a positive relationship between behavioral factors and clients' preference of insurance companies.

\subsection{Research Objectives}

This paper adapted three research objectives which were formulated from the statement of the problem and the preliminary literature review. No hypothesis test was done for this paper. Based on the following research objectives, this paper intended to determine the factors that drive clients' preference of insurance companies, as well as to identify the relative importance of these factors. The results obtained from the research objectives were then used to reveal theoretical similarities and differences in comparison with previous papers.

\subsection{Discussion of the Findings}

This paper investigated the determinants of insurance selection criteria by insurance clients in Keetmanshoop. By providing recent and extensive evidence on the factors of insurance preference criteria and to better inform insurance executives and authorities with insights into the kinds of services clients find most appropriate for their insurance needs. A total of 185 participants were sampled using a quantitative research method. Their responses on the importance of several different factors while choosing insurance companies were sought and analyzed. The demographic characteristics of the respondents provide sample respondents' profile in terms of gender and age range. Accordingly, majority of respondents were females compared to males. In terms of age range, participants between the age of 21 - 35 (85 participants) participated the most, followed by those between the age of 36 - 45 (63 participants), whilst participants between the age of 46 (37 participants) and above participated the least.

- The data shows that, innumerable respondents confirmed that their decisions were influenced by agents/brokers, whereas others pointed out that they were never influenced by anyone, they made their decisions on their own, through direct. Whilst, countable number of participants were influenced by peer groups in order to choose an insurer for their policies. Similarly, (Tadesse, 2014) [4] and (Rajkumar \& Kannan, 2014) [6] as well found out that, agents/brokers have major influence on clients compared to other factors.

- On a contrary, few clients have plans to switch from their insurance companies in the future. However, the majority, $87 \%$ of the respondents confirmed that they have no intentions of changing their current insurance providers, which means that, they intend to continue with their current insurance 
companies in the future. Correspondingly, (Tadesse, 2014) [4] found out that, various clients were happy with their companies and they never had any intentions of switch to other companies.

- In addition, clients were asked to elaborate why they have plans to switch from their insurance companies. It has been observed that the respondents would shift due to high insurance premiums, the decline of service quality from employees, as well as due to the lack of customer orientation and information provided. Surprisingly, according to (Tadesse, 2014) [4], clients had plans to switch due to high prices just similar to what the researchers found out. However, (Tadesse, 2014) [4] as well added that clients would switch because of the transfer to other locations, which the researchers did not come across in this paper.

- The results of the paper mainly show the level of importance that the respondents in Keetmanshoop associate with different attributes. Significantly, reliability is the most important factor clients consider when choosing insurance companies, whereas financially soundness of the company proved to be vital as well. Comparatively, (Suneja \& Sharma, 2015) [7] confirmed that, clients would always go for a financially sound organization. Furthermore, customer oriented is ranked at number 3 , with how well managed the company is, coming at number 4 , savings comes at number 5 , coming at number 6 is new schemes and attractive bonus, whilst other facilities is ranked the last variable considered by clients when choosing insurance companies.

- Using percentiles, clients are mostly influenced by agents' motivation. This means that the way agents motivate clients in choosing companies is very convincing. Secondly, clients are influenced by the trust they have in the companies (Trust in the company), there are certain companies that people trust mostly because of their reputation in the market. Whereas, some participants are influenced by attractive features of the policies.

- Identically, (Suneja and Sharma, 2015) [7] found out that clients' decisions are mostly influenced by promotional activities, which includes attractive features of the policies. To elaborate more, clients choose insurance companies after learning about the attractive features and benefits that the products offer when it matures. Other variables that influence the clients the least are, colleagues, friends, relatives and family members. Correspondingly, (Suneja and Sharma, 2015) [7] confirmed that colleagues have a very little impact on clients' decisions.

- In short, there is quite a positive relationship between the 3 variables (social, advertising and behavioral factors) and client's preference of insurers. Clients were as well influenced by all three variables with behavioral factors being the most influential. Behavioral factors include professionalism of agents, trust in the company, speed and efficient transactions, as well as the customer orientation. Furthermore, clients were as well influenced by advertising factors which is the second most influential factor. 
- Advertising factors consist of, promotional activities, attractive features of policies, reputation of the company as well as their familiarity. No evidence was found to suggest that social factors are less influencing, which include, colleagues, friends and relatives as well as family members. Meaning the findings by (Suneja \& Sharma, 2015) [7], that found that most clients were influenced by friends and relatives, still holds.

- Clients are as well influenced by product attributes, which are referred to as the features of the policies. Majority of the participants are satisfied with the products attributes, leaving only a few numbers of them unsatisfied with the product attributes. Identically, (Rajkumar \& Kannan, 2014) [6] stated in their findings that various clients are satisfied with the products attributes of their policies. Thus, there is a positive relationship between product attributes and clients' choice of insurance companies.

- Moreover, participants pointed out that they are highly satisfied with the product information provided to them, which illustrates a positive relationship between product information and clients' preference of insurance companies. Clients are positively influenced by product information. (Rajkumar \& Kannan, 2014) [6], identically elaborated that product information is crucial to clients regarding their data, which means, all the information significantly influence the clients somehow.

- Numerous clients are satisfied with the companies/products' services. However, few participants pointed out that they are not satisfied. Considering the majority of respondents, the relationship between companies/products services and clients' preference of insurance companies is positive. Companies/products' services influence clients in a positive way. (Rajkumar \& Kannan, 2014) [6] confirmed this point in their paper. The service that clients get can negatively/positively affect their decisions in the process.

- In order to examine the reasons clients would switch to other companies, the respondents pointed out the vital factors that influence clients in choosing insurance companies, which is popularity. Many clients stipulated that they would switch due to popularity. Whereas the second highest influencer has to low premiums, clients would want to shift to companies with affordable prices. Whilst other would consider high returns, future growth, as well as maximum risk coverage. Similarly, (Tadesse, 2014) [4] similarly found out that price is the most significant factor when it comes to clients' switching decisions.

\section{Conclusions and Recommendations}

\subsection{Conclusions}

The feedback from participants indicated that there is a positive relationship between clients and the factors (advertising, social and behavioral factors), this was illustrated by the $87 \%$ of participants that are very satisfied with their current insurers and they have no intentions of switching to other companies as 
they are comfortable with the price ranges, services, benefits, etc. However, 13\% of clients experienced a very negative relationship with the factors from their companies, which lend them with the intentions of switching to other companies and dissatisfactions. Most clients were influenced by agents/brokers as their level of awareness of insurers is moderate. The researchers recommended some vital points that insurance companies and agents/brokers should comprehend in order to be transparent and reputable in the business world, precisely the insurance industry.

\subsection{Limitations of the Study}

This paper focused on the town of Keetmanshoop in Namibia, other papers should focus on other towns to compare the factors that drive clients' preference of insurers. Furthermore, the study was limited to the economically active employed members of society and excluded entrepreneurs and the self-employed. In addition the study was limited to individuals while businesses also have insurance needs and could have contributed in a significant way towards the findings. Future studies may be conducted to look into the short comings of this study.

\subsection{Future Research Recommendations}

1) A study on the attitude of potential customers on influential factors can be carried out in order to figure out how potential customers think about (advertising, social and behavioral factors).

2) Since agents and brokers tend to mislead clients and misrepresent information, a dissertation on why brokers/agents mislead policyholders should be carried out.

3) An imminent study on why policyholders switch to other insurance companies should be carried out to help insurance companies to meet their clients' expectations and needs in order to prevent them from leaving.

4) A future research on the awareness of insurance companies by clients would be a success in helping individuals to figure out and explore other insurance companies and not just settling for the popular insurance companies regardless of the premiums.

5) Research exploring the impacts of brokers and agents on both the insurance companies and the policyholders will be a good one to carry out since agents/brokers play a major role in the insurance industry.

\section{Conflicts of Interest}

The authors declare no conflicts of interest regarding the publication of this paper.

\section{References}

[1] Bonner, M. (2018) Choosing the Right Insure. Business Insurance-Choosing a Company.

[2] Banerjee, G. (2015) Five Things to Consider While Choosing the Right Insurance 
Company.

https://m.economictimes.com/five-things-to-consider-whilechoosing-the-right-insu rnce-company/articleshow/46597607.cms

[3] Tucker, K. (2018) Social Factors of the Insurance Business.

[4] Tadesse, F. (2014) Insurance Selection Decision: Factors That Influence the Choice of Insurance Services in Selected Insurance Companies in Jimma Town. http://opendocs.ids.ac.uk/opendocs/handle/123456789/9784

[5] Mathur, D. and Tripathi, A. (2014) Factors Influencing Customers' Choice for Insurance Companies: A Study of Ajmer City. LOSR Journal of Business and Management, 16, 35-43. https://doi.org/10.9790/487X-16213543

[6] Rajkumar, M. and Kannan, N. (2014) Factor Affecting Preferences for Selection of Life Insurance Companies: An Empirical Study with Reference to Tamilnadu. International Journal of Accounting and Business Management, 2, 19-27.

[7] Suneja, A. and Sharma, K. (2015) Factors Influencing Choice of a Life Insurance Company. https://www.researchgate.net/publication/265351618

[8] Siddiqui, M. and Sharma, T. (2010) Analyzing Customer Satisfaction with Service Quality in Life Insurance Services. Journal of Targeting, Measurement and Analysis for Marketing, 18, 221-238. https://doi.org/10.1057/jt.2010.17

[9] Omni Convert (2018) What Is a Sample Size?

[10] Farooq, U. (2013) Types of Questionnaires: Study Lecture Notes.

[11] Gyasi, R. and Graff, C. (2015) African Population and Health. 